\title{
NíVEIS DE LACTATO EM PRATICANTES E NÃO PRATICANTES DE EXERCícIOS FíSICOS ANTES E APÓS EXERCíCIOS DE ALTA INTENSIDADE
}

\author{
Daisson Telles Rodrigues ${ }^{1}$, Carlos Vancini ${ }^{1}$, Patrícia Belin ${ }^{1}$, Rafael Jardim¹, Angelo Ricardo \\ Lavoratti $^{2}$, Flaiane Rodrigues Costa ${ }^{1}$, Vitor Antunes de Oliveira ${ }^{1}$ e Klauber Dalcero Pompeo ${ }^{3}$ \\ ${ }^{1}$ IDEAU, ${ }^{2}$ UNIASSELVI, ${ }^{3}$ UFRGS \\ daisson-rodrigues16@hotmail.com
}

Acesso DOI: http://dx.doi.org/10.34059/ciejop.2019v28i1-6

\section{RESUMO}

RODRIGUES, D.T; VANCINI, C; BELIN, P; JARDIM, R; LAVORATTI, A.R; COSTA, F.R; OLIVEIRA, V.A. e POMPEO, K.D. Níveis de lactato em praticantes e não praticantes de exercícios físicos antes e após exercícios de alta intensidade. Revista Científica JOPEF, Vol.28, n.1, pp.62-74, 2019. O Lactato é uma fonte de energia produzida naturalmente pelo organismo, quando a necessidade de energia é maior que a disponível, como nos exercícios de longa duração, por exemplo. A Glicose disponível nas células é quebrada através de um processo chamado Glicólise, que produz o piruvato, que ao não entrar em contato com oxigênio, transforma-se no Lactato. O Lactato é muitas vezes confundido como causador da fadiga muscular, porém sua única função se deve à produção de energia. $O$ estudo teve com objetivo comparar os níveis de Lactato sanguíneo antes e após atividades físicas de alta intensidade, tendo como objetos de pesquisa indivíduos que praticam e não praticam atividades físicas no seu dia a dia. Para a realização deste estudo desenvolveu-se uma pesquisa bibliográfica nas bases de dados do Google Acadêmico (Google Scholar) a partir das seguintes palavras-chave: Lactato, músculo, fadiga muscular e níveis de Lactato. E também a coleta de dados se deve à coleta de sangue antes e após exercícios de alta intensidade de praticantes e não-praticantes, e também a um questionário sobre alimentação e práticas de atividades físicas no dia a dia. Podendo assim, concluir que os níveis de produção de Lactato têm diferenças de acordo com o metabolismo, porém após exercícios físicos o que muda é o fato na eliminação rápida, pois quem tem uma rotina de exercícios obtiveram uma eliminação mais rápida do lactato no sangue do que quem não pratica atividades.

Palavras-chave: Lactato; Músculo; Fadiga Muscular

\section{ABSTRACT}

RODRIGUES, D.T; VANCINI, C; BELIN, P; JARDIM, R; LAVORATTI, A.R; COSTA, F.R; OLIVEIRA, V.A. e POMPEO, K.D. Níveis de lactato em praticantes e não praticantes de exercícios físicos antes e após exercícios de alta intensidade. Revista Científica JOPEF, Vol.28, n.1, pp.62-74, 2019. Lactate is a source of energy produced naturally by the body, when the need for energy is greater than that available, as in long-term exercises, for example. The glucose available in the cells is broken through a process called Glycolysis, which produces pyruvate, which, when it is not exposed to oxygen, becomes lactate. Lactate is often confused as causing muscle fatigue, but its only function is due to the production of energy. The objective of the study was to compare blood lactate levels before and after high 
intensity physical activities, with as research subjects individuals who practice and do not practice physical activities in their daily lives. For the accomplishment of this study, a bibliographical research was developed in the databases of Google Scholar from the following keywords: Lactate, muscle, muscle fatigue and lactate levels. And the practical research is due to blood collection before and after high-intensity exercises of practitioners and non-practitioners, as well as a questionnaire about diet and daily physical activity practices. It is possible to conclude that lactate production levels differ according to metabolism. However, after physical exercise, what changes is the fact of rapid elimination, since those who have an exercise routine obtained a faster elimination of lactate in the lactate. Blood than those who do not practice activities.

Keywords: Lactate; Muscle; Muscular Fatigue

\section{INTRODUÇÃO}

No contexto da ciência do exercício, o lactato é uma substância produzida naturalmente pelo nosso corpo e funciona como fonte de energia, e não é o causador da fadiga muscular, em estado de repouso a concentração de lactato no sangue é de 1 a $2 \mathrm{mmol} / \mathrm{L}$. No estado de repouso a concentração de lactato muscular está reduzida, porém ao ser realizado um exercício físico de alta intensidade o volume lactato aumenta significativamente.

Essa concepção buscou, através do proposto pelo Projeto de Aperfeiçoamento Teórico-Prático (P.A.T.P) do Instituto de Desenvolvimento Educacional de Passo Fundo (Faculdades IDEAU), o intercâmbio entre as diferentes disciplinas ministradas no semestre 2017/2. A partir do exposto, se faz necessário discutir a interdisciplinaridade, que começou a ser abordada a partir da Lei de Diretrizes e Bases n. ${ }^{0}$ 5.692/71 e tem se tornado mais presente nas práticas de ensino e aprendizagem, que visa integrar os conteúdos de forma a possibilitar que as diferentes disciplinas se entrelacem em um processo de interna fecundidade.

O curso de Educação Física constitui-se no desafio de habilitar profissionais para o campo de trabalho e produção do conhecimento, tendo como objeto de intervenção a cultura corporal humana, nos seus aspectos de Educação e Saúde. Também tem como objetivo a formação integral do ser humano, contribuindo na construção social voltada aos valores éticos e humanos e com a sociedade através dos conhecimentos científicos.

A fusão da teoria com a prática transforma o profissional em alguém realmente preparado para atender a demanda do mercado de trabalho. Foi realizado de modo a compor vivências do processo formativo e de elaborar concepções à luz 
do confronto entre as vivências e os estudos bibliográficos. O respectivo projeto fez a articulação entre todas as disciplinas do nível $\vee$ do curso de Educação Física, garantindo assim a vivência interdisciplinar das diferentes áreas do saber.

A pesquisa comparou os níveis de concentração de lactato entre adeptos de exercícios físicos e sedentário, antes e após a fadiga muscular ocasionada por exercícios de alta intensidade. Para tanto, essa pesquisa se justificou por identificar, analisar e correlacionar a concentração de lactato a prática de exercícios físicos de alta intensidade.

\section{METODOLOGIA}

A pesquisa aplicada se caracteriza por ser do tipo descritiva, pois a coleta de dados foi desenvolvida através de uma pesquisa de campo e levantamento de dados de caráter qualitativo e quantitativo, desenvolvendo uma descrição de fenômenos descritos em outras literaturas.

Os instrumentos de coleta de dados deram-se por coleta de sangue dos acadêmicos do nível $V$ do curso de Graduação Plena em Educação Física do Instituto de Desenvolvimento Educacional de Passo Fundo (Faculdades IDEAU), realizados a partir do equipamento Accutrend Plus Roche, com acompanhamento de um professor, trinta minutos anteriormente e trinta minutos posteriormente a atividades físicas de alta intensidade, proposta através de circuito desenvolvido pelos mesmos. Também se desenvolveu um questionário sobre alimentação e prática de atividades físicas.

A coleta buscou observar os níveis de lactato dos acadêmicos, antes e depois dos exercícios, selecionando os mesmos através do nível de exercícios físicos diários. Levou-se em consideração o padrão de 1 (uma) hora ou mais de exercícios para praticantes e de menos de 1 (uma) hora para não praticantes, números estabelecidos pela Organização Mundial da Saúde.

Os dados foram embasados em pesquisa bibliográfica, de revisões de literatura, onde os autores foram escolhidos por palavras-chave e pelos resumos de trabalhos. O trabalho foi desenvolvido a partir do tema proposto pelo Projeto de Aperfeiçoamento Teórico-Prático (P.A.T.P.) do Instituto de Desenvolvimento Educacional de Passo Fundo (IDEAU) no semestre 2017/2.

\section{RESULTADOS}

Fórum Internacional de Qualidade de Vida e Saúde - Balneário Camboriú/SC, 12 de outubro de 2019 
O lactato é uma substância produzida naturalmente pelo nosso corpo e funciona como fonte de energia, quando as quantidades de Adenosinatrifostato (ATP) está baixa, em estado de repouso a concentração de lactato no sangue é de 1 a $2 \mathrm{mmol} / \mathrm{l}$. A principal fonte de produção do lactato é a glicose. Através da cascata bioquímica a glicose se quebra em piruvato ocorrendo à produção de energia anaeróbia, já quando o piruvato se quebra ainda mais com o auxílio do oxigênio e se produz ainda mais energia denomina-se energia aeróbia. Porém quando as células perdem a capacidade de gerar energia, o piruvato se quebra e se transforma em lactato (Guyton apud Brooks et al,2000).

No estado de repouso a concentração de lactato muscular está reduzida, porém ao ser realizado um exercício físico de alta intensidade a demanda de ácido lático aumenta significativamente (Spriet apud Brooks et al,2000).

Caso o indivíduo consiga reduzir a produção de lactato ou diminua o tempo necessário para eliminação do lactato, consequentemente ele reduz a produção dos íons de hidrogênio que causa a redução do potencial Hidrogeniônico $(\mathrm{pH})$. Quando se trata de um atleta bem condicionado fisicamente o corpo reduz os níveis de lactato nas musculaturas recrutadas durante o esforço físico (Brooks et al, 2000).

Os exercícios físicos, em geral, utilizam uma grande quantidade de energia metabólica e sua capacidade está diretamente ligada a capacidade máxima de oxigênio. Além de substratos energéticos como glicose e ATP, a oxidação é uma forma muito potente na produção de energia em exercícios de longa duração.

A capacidade de realizar exercício submáximo por um prolongado espaço de tempo está diretamente relacionada com a capacidade máxima de consumir oxigênio (VO2 máx.), sendo este um índice do metabolismo oxidativo. Por se utilizar de outros substratos energéticos, além da glicose na geração de ATP, o metabolismo oxidativo é utilizado preferencialmente para fornecer energia de forma satisfatória durante longos períodos de esforço físico. (Benetti; Santos; Carvalho, 2000, p. 50)

O organismo ao estar exposto a exercícios físicos de baixa intensidade ou de curta duração consegue produzir energia através do aporte de oxigênio, porém em atividades de alta intensidade, o qual a demanda de oxigênio acaba sendo maior 
que o disponível, "a cadeia respiratória não consegue processar todo o hidrogênio ligado ao NADH. A liberação contínua de energia anaeróbica da glicólise depende da disponibilidade de NAD+ para oxidar 3-fosfogliceraldeído, caso contrário, o ritmo rápido da glicólise se esgota. (McArdle, 2016, p.146)

Com a necessidade de maior quantidade de energia inicia-se um processo no próprio músculo para degradação da glicose disponível, a qual através da glicólise (um processo catabólico) e de 10 reações enzimáticas, gera-se o piruvato. Segundo McArdle (2016, p. 146):

Durante a glicólise anaeróbica rápida, NAD+ "é liberado" ou regenerado quando pares de hidrogênio não oxidados "em excesso" combinam-se com o piruvato para formar o lactato. A formação de lactato requer uma etapa adicional (catalisada por lactato desidrogenase) em uma reação reversível.

Esse processo gera ATPs, os quais uma metade é utilizado pelo organismo e a outra metade volta a ser utilizada no processo. O lactato é uma fonte valiosa de energia química acumulado através do exercício físico, porém de todo o lactato formado a partir do piruvato, $5 \%$ dele é transformado novamente em glicose através da gliconeogenese, que por sua vez, voltará a ser transformada em piruvato, dando reinicio ao processo ainda no músculo.

Os arcabouços de carbono das moléculas de piruvato são formados novamente a partir do lactato durante a atividade (uma molécula de piruvato + dois hidrogênios formam uma molécula de lactato) ou são oxidados a energia, ou são sintetizados para glicose (gliconeogênese) no próprio músculo estriado esquelético ou no ciclo de Cori. O ciclo de Cori remove o lactato liberado pelos músculos ativos e o utiliza para reabastecer as reservas de glicogênio depletadas pela atividade física intensa. (McArdle, 2016, p.146)

Os outros 95\% de lactato serão liberados pelo músculo entrando na corrente sanguínea e sendo levado para o fígado. No fígado o processo continua gerando 
piruvato, que por sua vez sofre gliconeogênese gerando glicose, a qual será liberada novamente para a corrente sanguínea e será utilizada como fonte de energia durante o exercício intenso. Todo esse processo é denominado Ciclo de Cori.

Esse processo ocorre para que o organismo consiga manter a capacidade energética para sua atividade metabólica e também para o exercício realizado. "O Lactato proporciona um precursor para sintetizar carboidratos (através do Ciclo de Cori no fígado e nos rins) com a finalidade de preservar os níveis sanguíneos de glicose e atender as demandas energéticas do exercício concomitante. (McArdle, 2016, p.148)

Segundo Benetti, Santos e Carvalho alguns estudos mostram que a quantidade de lactato produzida durante o exercício é logo removida da corrente sanguínea, porém sua presença pode ser notada, o que poderia indicar que a liberação do mesmo é contínua. (2000, p. 53)

Com a fadiga muscular os níveis de ácido lático e hidrogênio $(H)$ nas células musculares e sanguíneas são aumentadas, ocorrendo a redução no $\mathrm{pH}$; o acúmulo de lactato pode estar associado à baixa quantidade de oxigênio na musculatura. Porém "é questionável a associação do lactato sanguíneo como agente causador da fadiga, pois a sua formação ocorre junto a outras modificações celulares como 0 acúmulo de íons de hidrogênio e, consequentemente, a diminuição no pH muscular (Ascensão,2002)."

O indivíduo que consegue reduzir a produção de lactato, ou diminuir o tempo de eliminação do mesmo consequentemente reduz a produção de íons de hidrogênio que causa a redução de $\mathrm{pH}$. Quando se trata de um atleta bem condicionado o corpo reduz os níveis de lactato durante o esforço físico (Brook et al, 2000).

A remoção de lactato pós exercício físico pode ser considerado fator importante para atletas que necessitam atingir níveis de performance elevados em um curto período de tempo (Franchini, 2002), pois necessitam de uma recuperação muscular rápida para que possam suportar a realização de diversas provas sequenciais (Ribeiro, 2002).

Uma atividade de alta intensidade muscular faz com que os músculos estriados esqueléticos necessitem de muita energia. Essa energia é adquirida pela 
"queima" de alimento junto com o uso de gás oxigênio. Mas, parte dessa energia necessária para a atividade muscular é obtida também por meio de um tipo de fermentação, um mecanismo de "queima" de alimento mais sem a utilização do gás oxigênio. Essa fermentação que ocorre no músculo é chamada de fermentação láctica, pois gera lactato como produto final. No periodo de repouso, ácido láctico presente no músculo da pessoa é "degradado", e as dores musculares desaparecem (Kube, 2010). Mas nem todas as dores musculares estão ligadas ao lactato, mais sim a fatores fisiológicos e microtraumas mecânicos causado pelo exercicio fisico, com dominio dos realizados de forma excêntrica (Neto et al., 2006). O trauma mecânico posto ao músculo leva á processos inflamatórios que causam dor e sensibilidade ao toque.

A fadiga muscular é fragmentado em Central(atingir a parte nervosa da contração muscular) e Periférica (apresenta um declinio dos processos bioquímicos e contráteis do músculo), fadiga central compreende-se no transporte do impulso nervoso aonde ocorre uma redução do número de unidades motoras ativas (composto pelo grupo de fibras musculares que são coordenadas por um único neurônio motor), e com isso diminui a frequência de disparo dos motoneurónios (neurônio que é capaz de fazer o músculo entrar em atividade), fadiga periférica ocorre por causa de uma falha ou limitação de um ou mais processos na unidade motora, isto é, nos neurônios motores, nervos periféricos, nas ligações neuromusculares ou fibras musculares (Ascensão, 2003).

Ao longo de um exercicio, o consumo energético do músculo aumenta assim há uma demanda maior de ATP. No entanto a produção de ATP deve ocorrer na mesma velocidade que é gasto pois os estoques são limitados, para que exercicio possa ser prolongado por mais tempo. Encontram-se três processos diferentes e intregrados que operam para satisfazer o consumo energético do músculo. $O$ Anaeróbio que pode ser fragmentado em alático e lático. $O$ alático traduz-se na quebra de creatina fosfato $(\mathrm{CP})$ e as moléculas de ATP que já estão presentes dentro do músculo. O lático compreende á combustão parcial da glicose ou glicogênio (é um polímero de resíduos de glicose, é o principal polissacarídeo de reserva em animais e é encontrado em todas as células. Ele está presente em maior concentração no fígado e no músculo). Com a quebra dessas duas moléculas vai gerar ácido lático com a sua conversão para lactato, aeróbio que atribui à combustão 
completa dos carboidratos (glicose e glicogênio), gorduras e em alguns casos proteínas na presença de oxigênio (Ascensão, 2003).

A fadiga muscular estar vinculado com o tipo, a intensidade e duração da atividade física, também do tipo de fibra que está sendo recrutado, o nível de treino e das condições ambientais de realização dessa atividade. As alterações no $\mathrm{pH}, \mathrm{a}$ variação na concentração de íons hidrogênio pode alterar diversas funções normais do corpo, modificando, por exemplo, a velocidade das reações metabólicas orientadas pelas enzimas. Exercicio com alta intensidade aumenta a concentração de íons $\mathrm{H}_{+}$, pelo aumento da produção de ácido lático assim ocorre uma diminuição no $\mathrm{pH}$, subsequente da rápida dissociação do ácido lático (Ascensão, 2003).

A temperatura e o fluxo sanguíneo podem estar associado a fadiga muscular, durante uma atividade mais extensa na qual a temperatura do corpo eleva-se a fadiga acontece de forma mais rápida em função da diminuição do volume sanguíneo, maior concentração de lático plasmático e consumo de glicogênio (Gomes, 2000).

O stress oxidativo é uma condição biológica em que ocorre desequilíbrio entre a produção de espécies reactivas de oxigénio e a sua desintoxicação através de sistemas biológicos que as removam ou reparem os danos por elas causados, outro fator que pode causar fadiga muscular, pessoas que realizam atividades física intensas e extensa, podem superar a capacidade do sistema antioxidante endógeno e decorrente disso ocorre graves lesões musculares e o stress oxidativo. Isso faz com haja uma redução no desempenho do treinamento, e possivelmente a fadiga muscular (Cruzat et al. 2007).

$O$ acumulo de produtos do metabolismo celula, principalmente dos resultantes da hidrólise do ATP (ADP, AMP, IMP, Pi, Amônia), a perda da homeostasia do ín $\mathrm{Ca2+}$, papel da cinética de alguns íons nos meios intra e extracelulares nomeadamente, o $\mathrm{K}+, \mathrm{Na}+, \mathrm{Cl}-, \mathrm{Mg} 2+$ (Ascensão, 2003). Também têm sido algumas das causas da fadiga muscular.

Através do estudo realizado na revisão bibliográfica, buscou-se a análise prática dos dados, com realização de testes rápidos de Lactato, realizados a partir do equipamento Accutrend Plus Roche. Os dados foram colhidos antes e depois de atividades físicas de alta intensidade.

Levou-se em consideração seis indivíduos, de ambos os sexos, sendo três deles praticantes de atividades físicas e três não-praticantes. Com os mesmos, Fórum Internacional de Qualidade de Vida e Saúde - Balneário Camboriú/SC, 12 de outubro de 2019 
desenvolveu-se uma entrevista com três perguntas, as quais buscavam entender um pouco sobre a alimentação e o tempo de descanso na noite e no dia do estudo. Através da entrevista, cinco dos indivíduos responderam que haviam se alimentado, sendo apenas um que não havia feito refeições adequadas, porém os seis afirmaram ter tido uma noite adequada de sono.

Os níveis de lactato, anterior aos exercícios, foram analisados através do que diz Lopes (1999, p.1), o qual delimita o nível normal de Lactato um número menor a 2,5mmol/L. Níveis entre 2,5mmol/L e 4,9mmol/L já são considerados níveis ligeiramente moderados, 5,5mmol/L a 9mmol/L, moderada, e acima de 10 nível severo. Os indivíduos ativos serão denominados "A", "B" e "C", e os não-ativos "D", "E" e "F".

Dos seis indíviduos, cinco deles apresentaram níveis ligeiramente moderados de lactato, sendo um deles apenas apresentando nível moderado, que pode ser explicado pela má alimentação antes das atividades, descritas pelo indíviduo. Após o primeiro teste foi realizado um circuito aeróbico de alta intensidade, envolvendo exercícios de força, locomoção e estabilidade. Após a realização do mesmo, a cerca de quinze minutos depois, foram realizados novos testes, medindo os níveis de lactato, pós-exercícios. A seguir, na figura 1, podemos ver a diferença entre os dois testes.

Anteriormente aos exercícios a média do nível de lactato do grupo dos praticantes totalizou $3,03 \mathrm{mmol} / \mathrm{L}$ e após os exercícios a média foi de $5,9 \mathrm{mmol} / \mathrm{L}$. Já os não-praticantes totalizaram uma média de $4,06 \mathrm{mmol} / \mathrm{L}$ antes dos exercícios e $9,73 \mathrm{mmol} / \mathrm{L}$ após os mesmos, como mostra a figura 2. 
Níveis de Lactato antes e após as atividades em mmol/L.

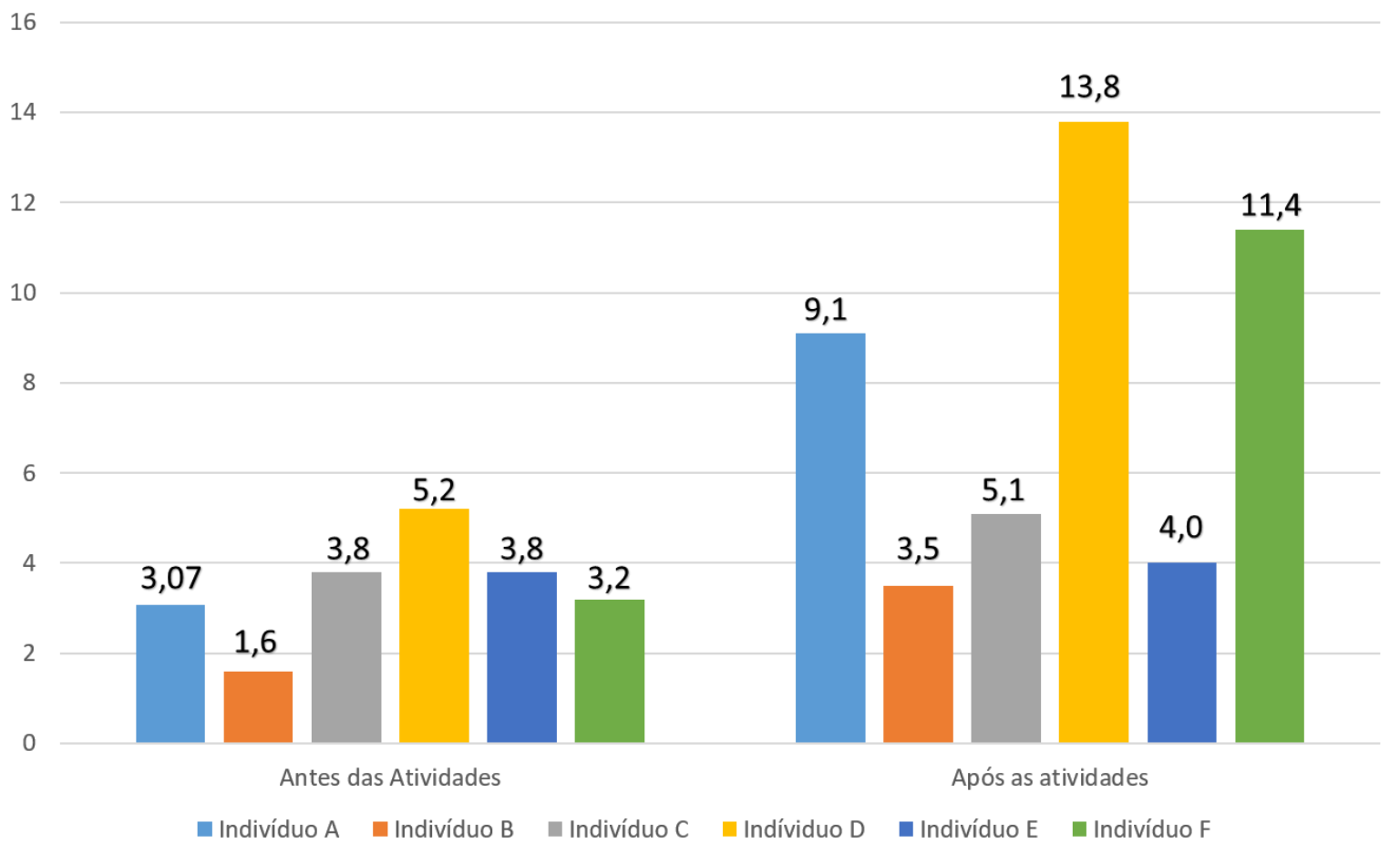

Figura 1: Gráfico da analise feita através dos dados anteriores e posteriores às atividades físicas de alta intensidade.

Média dos níveis de lactato antes e após atividades físicas em $\mathrm{mmol} / \mathrm{L}$

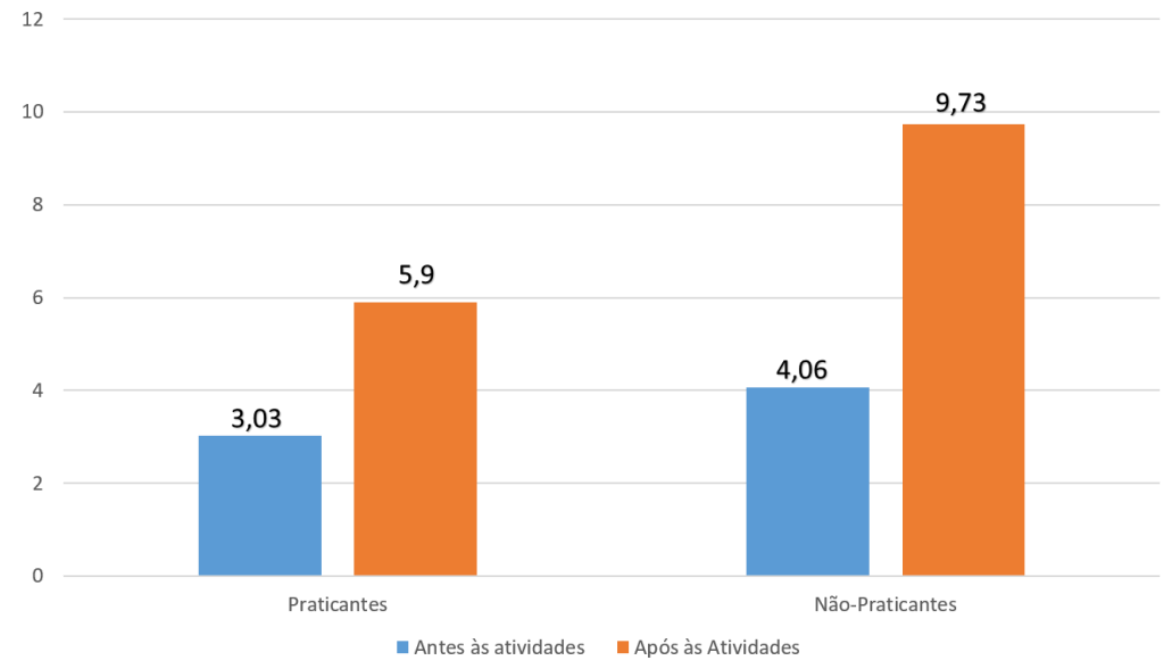

Figura 2: Gráfico da analise feita através das médias anteriores e posteriores às atividades físicas de alta intensidade.

A diferença entre os aumentos nos dois grupos foi de $45 \%$. O grupo de nãopraticantes apresentou um aumento $139 \%$, sendo que o grupo de praticantes foi 
observado um aumento $94 \%$. O grupo "não-praticante" teve mais de $100 \%$ de aumento, ou seja, mais do que o dobro dos valores pré-exercício. Podemos observar que o nível dos praticantes de atividades físicas foi definido um pouco menor que 0 dos não-praticantes.

Porém segundo Benetti (2000) "o lactato produzido é rapidamente removido do sangue, mas a concentração permanece constante, o que indica uma liberação contínua. Além disso, o nível de produção parece não se modificar de indivíduos não treinados para treinados. $O$ treinamento físico parece aumentar a captação e não alterar a produção."

Para melhor compreender essa ideia, seria necessário realizar um segundo teste para verificar se ouve mudança nos níveis após os exercícios, porém por questões financeiras foram realizadas apenas mais dois testes, em um indivíduo de cada grupo, após 10 minutos do primeiro teste. O indivíduo $A$ apresentou uma diminuição de 2,0 mmol/L, e o indivíduo $\mathrm{E}$, uma diminuição de $0,1 \mathrm{mmol} / \mathrm{L}$.

Conclui-se então, que os níveis de produção de Lactato têm diferenças de acordo com o metabolismo de cada indivíduo, porém após exercícios físicos o que muda é o fato na eliminação rápida, pois quem tem uma rotina de exercícios obtiveram uma eliminação mais rápida do lactato no sangue do que quem não pratica atividades.

\section{CONCLUSÃO}

O lactato é produzido em todos os organismos vivos que se utilizam da glicose como fonte de energia, já que através do Ciclo de Cori é possivel gerar energia quando os níveis de ATP estão baixos, possibilitando a execução de atividades de alta intensidade ou de grande duração.

O estudo apresentou algumas dificuldades na sua execução, partindo do fato do não conhecimento da forma de manuseio do aparelho Accutrend Plus Roche, pois o mesmo não é um equipamento comum e de manuseio no dia a dia. Houve também a dificuldade de coleta do sangue, partindo do fato que havia apenas um aparelho para coleta, impactando na demora da mesma, podendo, o trabalho, não apresentar resultados exatos do lactato presente no sangue. Outra dificuldade foi a de desenvolver as atividades do circuito corretamente, pois alguns dos indivíduos apresentavam dificuldades para a realização do mesmo, não servindo para alguns como alta intensidade, isolando os mesmos da pesquisa.

Fórum Internacional de Qualidade de Vida e Saúde - Balneário Camboriú/SC, 12 de outubro de 2019 
Portanto, o lactato não pode ser definido como um causador da fadiga muscular e sim como uma fonte de energia. O nível do mesmo em praticantes e não-praticantes antes de exercícios apresentam pouca diferença, mas após o mesmo houve um aumento nos dois grupos de $45 \%$. O grupo de não-praticantes apresentou um aumento $139 \%$, sendo que o grupo de praticantes foi observado um aumento $94 \%$. Notou-se também que os níveis pós exercícios podem ser alterados com o condicionamento físico, pois o que muda é a rapidez de captação e transformação do mesmo em glicose.

\section{REFERÊNCIAS}

ASCENSÃO, A. Magalhães, J. Oliveira, J. Duarte, J. Soares. Fisiologia da Fadiga Muscular. Delimitação conceptual, modelos de estudos e mecanismo de fadiga de origem central e periférica. Revista Portuguesa de Ciências do Desporto, 106123, 2003.

BENETTI, M.; SANTOS, R. T.; CARVALHO, T. Cinética de lactato em diferentes intensidades de exercícios e concentrações de oxigênio. Revista Brasileira de Medicina do Esporte, v.6, № 2. Mar/Abr 2000.

BROOKS G. A. Current concepts in lactate exchange. Med Sci Sports Exerc; 23(8):895-906, 1991.

CRUZAT Et al. Aspectos atuais sobre estresse oxidativo, exercícios físicos e suplementação. Revista Bras Med Esporte, vol. 13, № 5, 2007.

FRANCHINI, E., Teste anaeróbio Wingate conceitos e aplicações. Revista Mackenzie de Educação Física e Esporte, v.1, n.1, p. 11-27, 2002.

GOMES, J. T.. Relação de alguns suplementos nutricionais e desempenho físico. Arquivos Latino Americanos de Nutrição, 2000.

KUBE. Fisiologia da fadiga, suas implicações na saúde do aviador e na seguração na aviação. Revista Conex. SIPAER, v. 2, n. 1, 2010;

LOPES, V. M. B. Interpretação do Lactato no sangue. Disponível em: <http://files.agenorjunqueira.webnode.com.br/2000000818934b89b22/Interpreta\%C3 \%A7\%C3\%A30\%20Lactato.docx>. Acesso em: 23 out 2017

MCARDLE, W. D.; KATCH, F. I.; KATCH, V. L. Fisiologia do Exercício: Nutrição, Energia e Desempenho Humano. Rio de Janeiro: Guanabara Koogan, 8르, ed, 2016. 
NETO, J. M. F. A., MELO, P., FILHO, J. P. A., et al. Desmistificando a Ação do Lactato nos Eventos de Dor Muscular Tardia Induzida pelo Exercício Físico: Proposta de uma Aula Prática Revista Brasileira de Ensino de Bioquímica e Biologia Molecular Biblioteca Digital de Ciências, Artigo 1, Edição 02/2006, 18 mar. 2006.

RIBEIRO, L. S. P.; TOURINHO, F. H. Remoção de lactato sanguíneo em diferentes velocidades em esteira rolante. Revista Médica HSVP, v. 14, p. 7-12, 2002

TRICOLI, Valmor. Mecanismos envolvidos na etiologia da dor muscular tardia. Revista Brasileira de Ciência e Movimento, vol. 9, n. 2, abril. 2001. 